\title{
Does the social status of the elderly impact morbidities among them? - A cross sectional Study in a district of Gujarat
}

\section{Shashwat S Nagar ${ }^{1}$, Noopur S Nagar ${ }^{2}$, Hirenkumar B Patel ${ }^{3}$, Darshan Mahyavanshi ${ }^{4}$, SS Nagar ${ }^{5}$}

${ }^{1}$ Professor, Department of Community Medicine, Parul Institute of Medical Sciences Parul University, Vadodara, Gujarat;

${ }^{2}$ Assistant Professor, Department Obstetrics and Gynaecology, Parul Institute of Medical Sciences, Parul University, Vadodara, Gujarat; ${ }^{3}$ Associate Professor, Department of Community Medicine, Nootan Medical College \& Research Center, Sankalchand Patel University, Visnagar, Gujarat; ${ }^{4}$ Associate Professor, Department of Community Medicine, Namo Medical Education \& Research Institute, Dadra and Nagar Haveli; ${ }^{5}$ Ex-Professor and Head, Department of Community Medicine, C.U.SHAH Medical College, Surendranagar.

\begin{tabular}{|c|c|c|c|c|c|c|c|c|}
\hline Abstract & Introduction & Methodology & Results & Conclusion & References & Citation & \multicolumn{2}{|c|}{ Tables / Figures } \\
\hline \multicolumn{9}{|c|}{ Corresponding Author } \\
\hline \multicolumn{8}{|c|}{$\begin{array}{l}\text { Dr. Hirenkumar B Patel, G-102, Darshanam Vertica, Near Vaikunth-1 residency, Waghodia Road, Vadodara, } \\
\text { Gujarat-390025 } \\
\text { E Mail ID: hirendr85@gmail.com }\end{array}$} & 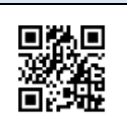 \\
\hline
\end{tabular}

\section{Citation}

Nagar SS, Nagar NS, Patel HB, Mahyavanshi D, Nagar SS. Does the social status of the elderly impact morbidities among them? - A cross sectional Study in a district of Gujarat. Indian J Comm Health. 2021;33(3):456-461. https://doi.org/10.47203/IJCH.2021.v33i03.009

Source of Funding: Nil Conflict of Interest: None declared

\section{Article Cycle}

\begin{tabular}{|c|}
\hline Received: 22/05/2021; Revision: 05/06/2021; Accepted: 11/08/2021; Published: 30/09/2021 \\
\hline This work is licensed under a Creative Commons Attribution 4.0 International License. \\
\hline
\end{tabular}

\section{Abstract}

Background: The aging population is both medical \& sociological problem for the country and they suffer with high rates of morbidity and mortality. So Social factors lay a significant impact on the health practices and this study will help us to understand and evaluate their health problems of elderly. Aims and Objective: 1 . To assess the social status of elderly population. 2. To associate the findings with morbidities of elderly Methods: A cross sectional study was carried out in urban and rural area of Surendranagar district among 611 elderly, using a predesigned and pre tested questionnaire by directly questioning the subjects with oral and written consent. For selection of the area, in both areas, the sampling units were enumerated and samples were collected by using simple random sampling, data was entered and analyzed using MS excel 2007. Result: Nearly $60 \%$ of the subjects were currently unemployed and the predominant family system was 3 generation family. Majority of the families in the urban areas were from social class 4 , whereas in the rural areas were from social class 5. Having poor social score had a statistically significant association with presence of morbidity in elderly both areas. Conclusions: Majority of elderly in both urban and rural areas had a poor social status. Role of the family and social structure on the health of the elderly can be clearly established. However, support structure must be developed in our social system in a way that the destitute and dependent elderly are taken care of by either government system or social organizations like NGOs and old age home.

\section{Keywords}

Socioeconomic Status; Elder People; Rural; Social Score; Morbidities; Informed Consent

\section{Introduction}

Ageing is natural and an unavoidable sequel of adulthood during human life. In previous years, elderly were taken care of in a joint family structure. Urbanization and industrialization has drastically changed social and familial life. Because of that, joint family has disappeared and people in the society are becoming more and more individualistic. So, the old people are facing the problem of adjustment to their families. (1)
An aging population puts an increased burden on the resources of a country and has raised concerns at many levels for the government of India. The aging population is both medical and sociological problem for the country. So it has become very difficult task for policy makers to address the geriatric care. (2)

The older people in India are much more vulnerable because government spending less money on social security system. Mainly in urban area, older people mainly depend on domestic help to meet their basic needs. And 
because of these reasons social isolation and loneliness has increased among elderly. (3)

Researchers also explain that elder people health outcomes can also explained by social factors such as race, income, and education are among the strongest predictors of morbidity and mortality. (4)

Unfortunately old age has now become a prevalent social problem. In view of this background, this small effort was made to understand social situation and its relation with morbidity among the Geriatric population of Surendranagar district of Gujarat. This study will help us to understand and evaluate their health problems, so that a comprehensive health care plan covering all aspects of preventive, promotive, curative, and rehabilitative services can be planned.

\section{Aims \& Objectives}

1. To assess the social status of elderly population.

2. To associate the findings with the existing morbidities

\section{Material \& Methods}

For selection of the area, in both the urban and rural areas, the sampling units were enumerated and samples were collected from them. For Rural data collection, out of all the 12 talukas in surendranagar district, one taluka was selected by using simple random sampling, which came out to be Sayla taluka. Of all the villages in the taluka, Sayla village was selected using similar sampling process. In the Urban areas, after enumerating all the wards, Ward No. 7 was selected using simple random sampling. The estimated geriatric population combined in both Urban and Rural areas amounted to 12,220 (7\% of geriatric population as per Census 2001), out which $5 \%$ was selected as sample as per the availability of resources. This came out to be 611 elderly subjects which were selected equally from both urban (305) and rural (306) areas. Study was conducted for 6 months. The study was cross sectional study by directly interviewing the subjects with oral and written consent. Self-structured and pretested Performa was validated and then used, consisting of socio demographic profile and social status of elderly. Data was entered and analysed using MS excel 2007. The permission from ethical committee was taken prior to the commencement of the study.

A social status score of the elderly was created as a comprehensive index of their social status including 6 variables which evaluated their social status based on their interaction, acceptance and being cared for in the community. The final computed score was generated after summing up individual scores from the responses and thereafter categorized as Good (3), Average(2) and Poor (1) on the basis of the individual responses given to each social variable (Good: 15 - 18, Average: 11-14 and Poor : 06-10).

\section{Calculation of Social Score}

$$
\text { Variable }
$$

\begin{tabular}{|l|l|}
\hline $\mathbf{3}^{\text {rd }}$ generation & 3 \\
\hline Joint & 2 \\
\hline Nuclear & 1 \\
\hline 2. Socio-economical Classification & \\
\hline Class 1 & 3 \\
\hline Class 2 & \\
\hline Class 3 & 2 \\
\hline Class 4 & 1 \\
\hline Class 5 & \\
\hline 3. Do you stay with your children & 3 \\
\hline Yes & 1 \\
\hline No & \\
\hline $\begin{array}{l}\text { 4. Do you children visit you } \\
\text { regularly? }\end{array}$ & \\
\hline Yes & 3 \\
\hline No & 1 \\
\hline $\begin{array}{l}\text { 5. Routine Interaction with family } \\
\text { members }\end{array}$ & \\
\hline Yes & 3 \\
\hline No & 1 \\
\hline $\begin{array}{l}\text { 6. Attitude of family members } \\
\text { towards you }\end{array}$ & \\
\hline Respectable & $11-14$ \\
\hline Negative & $6-10$ \\
\hline Misbehaviour & 2 \\
\hline Scoring System & 1 \\
\hline Good & with AICPI 741. \\
\hline Average & \\
\hline Poor & \\
\hline * Modified BG Prasad classification & \\
\hline
\end{tabular}

The housing score was calculated for each individual house hold visited during data collection. Different factors were analysed and the housing score was allotted to each factors. A total housing score was calculated on the basis of addition of the individual scores.

\begin{tabular}{|l|l|}
\hline $\begin{array}{l}\text { Calculation of Housing Score } \\
\text { TYPE OF HOUSE }\end{array}$ & SCORE \\
\hline Kaccha & 1 \\
\hline Semi- Pukka & 2 \\
\hline Pukka & 3 \\
\hline NO. OF ROOMS & SCORE \\
\hline 1 Room & 1 \\
\hline 2 Rooms & 2 \\
\hline >2 Rooms & 3 \\
\hline PER CAPITA FLOOR & SCORE \\
\hline SPACE & 1 \\
\hline <50 Sq feet & 2 \\
\hline 50-100 sq feet & 3 \\
\hline >100 sq feet & SCORE \\
\hline VENTILATION & 1 \\
\hline Inadequate & 2 \\
\hline Adequate & SCORE \\
\hline LIGHTING (Natural) & 1 \\
\hline Inadequate & 2 \\
\hline Adequate & SCORE \\
\hline LIGHTING (Artificial) & 1 \\
\hline Inadequate & 2 \\
\hline Adequate & \\
\hline & \\
\hline
\end{tabular}




\begin{tabular}{|c|l|}
\hline SANITARY LATRINE & SCORE \\
\hline Not available & 0 \\
\hline Available but shared & 1 \\
\hline Available individual & 2 \\
\hline WATER SUPPLY & SCORE \\
\hline Unsafe & 0 \\
\hline Safe shared & 1 \\
\hline Safe individual & 2 \\
\hline TOTAL SCORE & \\
\hline GRADING & SCORE \\
\hline Good & $15-19$ \\
\hline Fair & $07-14$ \\
\hline \hline Poor & $\leq 6$ \\
\hline
\end{tabular}

It was also seen that association of Social score \& its impact on Morbidities was found to be statically significant using chi-square test at $5 \%$ level of significance in both urban and rural area.

\section{Results}

Majority of the subjects in the urban area were in the age group up to 75 years, where as in the rural area most of the subject aged more than 65 years. In the urban area, majority of subject were females, where as in rural area proportions were same.

Nearly $78 \%$ of the subjects were from Open category followed by $12 \%$ from OBC and $9 \%$ from SC in the urban area. Only about $54 \%$ of the subjects in the rural areas were from Open Category, followed by $17 \%$ from ST and $16 \%$ from SC. Nearly $60 \%$ of the subjects in both urban and rural area were currently unemployed. Majority of the subject in urban area were professional or semiprofessional where those in rural area were skilled or unskilled workers. With respect to education, $28 \%$ in urban and $58 \%$ rural were illiterate. Majority of the literate in both the areas were educated up to primary. About $14 \%$ in urban, $4 \%$ in rural were graduates. Most of the subjects were married with about $30 \%$ in both areas, who were widow/widower.

The (Table 1) shows that the predominant family system in the rural was 3 generation family (44\%) followed by joint family (36\%), whereas in urban areas, all the three types of families had nearly similar pattern with slight dominance of 3 generation system. Also the table explains that majority of the families in the rural area $(53 \%)$ had poor housing score, whereas in urban areas, majority of families had average and nearly $33 \%$ had good housing score.

Modified Prasad's Classification was used to calculate the social class of the families in both urban and rural areas. Majority of the families in the urban areas were from social class $4(29 \%)$, followed by those from social class 3 (24\%) whereas in the rural areas, majority of the families were from social class $5(47 \%)$ followed by those from social class 4 (26\%).

(Figure 1) shows, that $29 \%$ in urban and $26 \%$ in rural were financial independent. About $16 \%$ in both urban, rural were partly dependent for their finances on their spouse

or children; whereas more than half i.e. $55 \%$ in urban and $58 \%$ in rural were financially totally dependent on others. The financial dependency were asked to the study subjects, majority in the urban area were dependents on their spouse (52\%) followed by sons (43\%) and daughter (5\%). In the rural areas a vast majority were dependently on their sons (74\%) followed by spouse $(20 \%)$ and their grandchildren (3\%).

The (Table 2) depicting response to some personal questions in which around $91 \%$ of urban male compared with $81 \%$ of rural male were staying with their children. $90 \%$ of urban females and $82 \%$ rural females were staying with children. In total, $90.49 \%$ of urban population and $81 \%$ of rural population opted to stay with children.

There were 29 subjects in the urban and 58 subjects in the rural that did not stay with their children Out of them, in the urban $54.54 \%$ and $33.33 \%$ of males and females stayed with their spouse respectively; and nearly $44 \%$ of males and $56 \%$ of females of rural stayed with their spouses. About $31 \%$ in urban and $5.5 \%$ in rural stayed alone. Only about $14 \%$ from the urban and $38 \%$ of rural visited their children regularly.

When enquired about the interaction with other family members, nearly $95 \%$ of urban and $87 \%$ of rural gave a positive response. In the urban, nearly $75 \%$ said that the attitude of the family members towards them was respectable whereas, only $50 \%$ from the rural said that the attitude was respectable. About $20 \%$ of urban and nearly $42 \%$ of rural subjects said that they felt neglected by the family members.

When asked about their attitude towards life, about 73\% had a happy attitude towards life, and nearly $26 \%$ were unhappy about some issue or the other, nearly $1 \%$ had loss of interest towards life in urban areas. In contrast, only $55 \%$ of rural said they were happy. Nearly $41 \%$ were not happy and about $4 \%$ said they had lost interest in life. (Table 3) explains that as the sample was taken both urban and rural area, the quality of social conditions among the elder people was predominantly poor with a majority of them showing poor condition (43\% in urban and $45 \%$ in rural) whereas (26\% in urban and $27 \%$ in rural) showed average and only (30.5 \% in urban and $26 \%$ in rural) showed as having in good conditions.

(Table 4) explains the impact of social conditions on prevalent morbidities, it can be seen that both in urban and rural area elderly having good score had lesser prevalence of morbidities as compare to average and poor score. This was found to be statically significant using chisquare test at $5 \%$ level of significance in both urban $(X 2=8.61, P<0.05)$ and rural area $(X 2=20.98, P<0.05)$. This shows the impact of social structure and social factors on the health and morbidities of elderly. The chief morbidities included Depression and common mental disorders, hypertension, diabetes, renal diseases, cardiac morbidities and ophthalmic morbidities. 


\section{Discussion}

Since ancient times, India is known and recognized for its strong social structure. This structure includes Joint family system and social values wherein the elderly are given respect and importance for their varied life experiences. The current study aimed at finding out the social status and its impact on morbidities. It was seen keeping various variables into consideration that the social structure plays a major role in morbidity pattern. Socially many elderly were found to have compromised social value as they were either not cared by their family members or had minimal interactions with them. The evolving nuclear family system has also isolated the elderly as seen in the present study.

As the study was conducted in the rural and peri-urban areas, the Joint family system was found predominantly and those living in that social system had better health and lesser morbidities maybe due to improved mental health. Other factors of significance were financial dependency, attitude of family members towards the elderly primarily talking about behavioural patterns and socio-economic classification. All of these factors play their roles directly or indirectly on the social status of the elderly and the importance given to them in the current structure. The feeling of worthlessness and unwanted can play a big role in the various morbidities found among the elderly.

As for gender, Census 2011 indicated that, overall percentage for older population is $8.6 \%$, in which $8.2 \%$ was male and $9 \%$ was female. A similar pattern was also observed by Munshi et al in which, the feminization of the elderly population, with majority being women and rest being men. (5) A study by Vijayanchali S. S et al (6) showed reversal of the result in which male proportion of elder population in study group was higher as compare to female.

In our study, nearly $60 \%$ of the subjects in both urban and rural area were currently unemployed. Also a study by Gaurav RB et al (7) also explained that $38.6 \%$ were retired or unemployed and currently not involved in an active profession. In our study, with respect to education, $28 \%$ in urban and $58 \%$ rural were illiterate and majority of them educated up to primary. A study by Vijayanchali S. S et al (6) also explained that 30\% were graduated, $20 \%$ educated up to primary. This difference may be due to different study setting and nature of the sampling.

In the present study, the predominant family system in the rural was 3 generation family (44\%) followed by joint family (36\%), whereas in urban areas, all the three types of families had nearly similar pattern with slight dominance of 3 generation system. A survey done by Nesa $M$ et al (1) also explain that elderly men and women both came from nuclear and joint families. $40 \%$ of the elderly from both urban and rural areas came from nuclear family. Over $45 \%$ of the respondents were from joint family in rural areas as opposed to about $50 \%$ from urban areas.

In our study, majority of the families in the urban areas were from social class $4(29 \%)$, whereas in the rural areas, majority of the families were from social class $5(47 \%)$ followed by those from social class $4(26 \%)$. This could be as an influence of more total income of the families in urban area than rural area. The present study showed about $91 \%$ of subjects in urban area and $81 \%$ in rural area living with their children. The NSS data indicated that children support more than $70 \%$ of the elderly. In terms of living arrangements, around $3.45 \%$ of elderly live alone. While $75 \%$ of elderly men live with their spouses, only $39 \%$ of elderly women live with their spouses and the rest live with their children.(8)

In the present study, it was seen that having poor social score had a statistically significant correlation with presence of morbidity in elder people both in urban and rural area. A study by R Fernandez et al (9) also explains that social support has an important impact on the health and well-being of older people. Also study by WHO health profile of the elderly in South East Asia region also showed same result that the prevalence of morbidity was more among the elderly who belonged to the lower socioeconomic class than those who belonged to the higher socioeconomic class and this difference was found to be highly significant $(P<0.01)$. (10) Another study by George, et al also explain in their result that the morbidity was found to be more among the elder people who belonged to the lower socioeconomic status than those who belonged to the higher social status and this difference in the prevalence of morbidity was found to be highly significant $(P<0.01)$. (11)

\section{Conclusion}

It can be concluded from the study that the majority of elderly in both urban and rural area had a poor social status. Having poor social score plays a significant role in presence of morbidity in elderly population. Role of the family and social structure on the health of the elderly can be clearly established from this study. Family should take responsibility to look after the elderly. However, it may so happen that family may not always be responsive and sensitive towards these issues, therefore support structure must be developed in our social system in a way that the destitute and dependent elderly are taken care of by either government system or social organizations like NGOs and old age home. Elderly have their own set of health problems which need special attention. As the geriatric clinic currently at district hospital levels. It is high time that these services are amalgamated in the primary health care system. Capacity building of heath care staff including frontline workers will be crucial for the successful implementation at grass root level. 


\section{Recommendation}

Community-based camps and screening exercises must be carried out at regular intervals to find out the patterns and trends of morbidities. Strengthening of the elderly care along with provision of primary care as envisioned in Ayushman Bharat needs to be focused on to serve the elderly. Special package of services for public sector and insurance for availing health services in private sector must be set up and should be an integral part of the upcoming health policy. Healthy aging is not only a proxy but a very important indicator of a country's health status and health priorities.

\section{Limitation of the study}

1. The study participants couldn't be followed up over a given period of time and the morbidity were assessed only in cross sectional manner

2. Data could be collected from only one taluka in rural and one ward in urban, a larger sample couldn't be studied due to limitation in resources

3. Laboratory investigations related to morbidities couldn't be carried out

\section{Relevance of the study}

Morbidity assessment of the elderly population should be carried out from time to time. This is often not being regularly done. As it is one of the integral components of the comprehensive primary health care, this study will work as a baseline for carrying out similar assessments in future. This will help in planning of the health services for the elderly in the areas of the data collection and the whole district thereafter.

\section{Authors Contribution}

All authors contributed equally.

\section{Acknowledgement}

Highly thankful and duly acknowledge the sarpanch and officers of the ward office and taluka and gram panchayat where the data collection was carried out.

\section{References}

1. Mirza Amirun Nesa, Md. Emdadul Haque, Dr. N. M. R. Siddiqua and M. Imdadul Haque Social Status of Elderly People in Health Perspective: A Comparison of Rural and Urban Area. IOSR Journal of Humanities and Social Science 2013; 18(6):83-94.

2. Mane $A B$ (2016) Ageing in India: Some Social Challenges to Elderly Care. J Gerontol Geriatr Res 5: [Internet]. [Cited 23/09/2020]. Available from: http://dx.doi.org/10.4172/2167-7182.1000e136.

3. Population Ageing and Health in India. Centre for Enquiry into Health and Allied Themes, Mumbai.2006 [Internet]. [Cited 10/09/2020]. Available from: http://www.cehat.org/cehat/uploads/files/ageing\%281\%29.pdf

4. Kim, J. \& Durden, E. Socioeconomic status and age trajectories of health. Social Science \& Medicine 2007; 65: 2489-2502.

5. Munshi Yl, Iqbal M, Rafique H, Ahmad Z. Geriatric morbidity pattern and depression in relation to family support in aged population of Kashmir valley. Internet J Geriatr Gerantol 2008; 4:18-22.

6. Vijayanchali, S. \& Gandhi, E.Arumuga. Socio-Economic and Health Status of Elderly. Journal of Research, Extension Development 2012; 1:177-18.

7. Gavrav R B, S. Kartikayan. Problem of geriatric population in urban area Thane- Bombay. Bombay Hospital Journal. 2002; 44(1): 47-51.

8. Situation Analysis of the Elderly in India, 2011. Available from: http://mospi.nic.in/sites/default/files/publication reports/elderly in india.pdf.

9. Fernandez-Ballesteros R. Social support and quality of life among older people in Spain. J Soc 2002; 58: 645-659.

10. WHO. Health of the elderly in South east Asia - A profile. New Delhi: World Health Organization, Regional Office for South east Asia; 2004. p. 31 5. [Internet]. [Cited 25/07/2020,]. Available from: http://apps.who.int/iris/bitstream/10665/205245/1/B1462.pdf.

11. George LS, Deshpande S, Krishna Kumar MK, Patil RS. Morbidity pattern and its sociodemographic determinants among elderly population of Raichur district, Karnataka, India. J Family Med Prim Care 2017; 6:340-4.

\section{Tables}

TABLE 1 DISTRIBUTION OF THE FAMILIES ACCORDING TO SOCIAL FACTORS

\begin{tabular}{|c|c|c|c|c|}
\hline & \multicolumn{2}{|c|}{ Urban (N=202) * } & \multicolumn{2}{|c|}{ Rural $(\mathrm{N}=190)$ * } \\
\hline & Number & $\downarrow \%$ & Number & $\downarrow \%$ \\
\hline \multicolumn{5}{|l|}{ Type of family } \\
\hline Nuclear & 63 & 31 & 38 & 20 \\
\hline Joint & 60 & 30 & 68 & 36 \\
\hline 3 Generation & 79 & 39 & 84 & 44 \\
\hline \multicolumn{5}{|l|}{ Housing score } \\
\hline Good & 67 & 33 & 36 & 19 \\
\hline Average & 107 & 53 & 53 & 28 \\
\hline Poor & 28 & 14 & 101 & 53 \\
\hline \multicolumn{5}{|l|}{ Social Class } \\
\hline Class 1 & 18 & 9 & 10 & 5 \\
\hline Class 2 & 32 & 16 & 8 & 4 \\
\hline Class 3 & 48 & 24 & 34 & 18 \\
\hline Class 4 & 59 & 29 & 49 & 26 \\
\hline Class 5 & 45 & 22 & 89 & 47 \\
\hline
\end{tabular}

*The number of families from where the study population originated were taken into account which was 202 in urban and 190 in rural areas. 


\section{TABLE 2 TABLE DEPICTING RESPONSE TO THE PERSONAL QUESTIONS}

\begin{tabular}{|c|c|c|c|c|}
\hline & \multicolumn{2}{|c|}{ Urban $(\mathrm{N}=305)$} & \multicolumn{2}{|c|}{ Rural ( $\mathrm{N}=306)$} \\
\hline & No. & $\downarrow \%$ & No. & $\downarrow \%$ \\
\hline \multicolumn{5}{|l|}{ 1. Do You Stay with Your Children? } \\
\hline Yes & 276 & 90.49 & 248 & 81.04 \\
\hline No & 29 & 9.51 & 58 & 18.95 \\
\hline 2. If no, with whom do you stay? & \multicolumn{2}{|c|}{ Urban( $N=29)$} & \multicolumn{2}{|c|}{ Rural : $\mathbf{N}=\mathbf{5 8}$} \\
\hline a. Spouse & 12 & 41.37 & 43 & 78.18 \\
\hline b. Relatives & 8 & 27.58 & 6 & 10.59 \\
\hline c. Alone & 9 & 31.03 & 3 & 5.45 \\
\hline d. Son/Daughter in law & 0 & 0 & 3 & 5.45 \\
\hline \multicolumn{5}{|l|}{ 2-a: Do your children regularly visit? } \\
\hline Yes & 4 & 13.79 & 22 & 37.93 \\
\hline No & 25 & 86.20 & 36 & 62.06 \\
\hline 3. Interaction with family members & \multicolumn{2}{|c|}{ Urban $(\mathrm{N}=305)$} & \multicolumn{2}{|c|}{ Rural $(\mathrm{N}=306)$} \\
\hline Yes & 287 & 94.49 & 255 & 87.62 \\
\hline No & 18 & 5.81 & 36 & 12.38 \\
\hline \multicolumn{5}{|c|}{ 4. Attitude of family members towards you } \\
\hline Respectable & 227 & 74.44 & 152 & 49.67 \\
\hline Neglected & 60 & 19.67 & 129 & 42.15 \\
\hline Misbehaviour & 18 & 5.9 & 25 & 8.18 \\
\hline \multicolumn{5}{|l|}{ 5. Attitude towards life } \\
\hline Happy & 222 & 72.78 & 168 & 54.9 \\
\hline Not happy & 80 & 26.22 & 126 & 41.17 \\
\hline Loss of interest & 3 & 0.98 & 12 & 3.92 \\
\hline
\end{tabular}

TABLE 3 SOCIAL SCORE OF STUDY SUBJECTS

\begin{tabular}{|c|l|l|}
\hline Score & Urban (\%) & Rural (\%) \\
\hline Good (15 -18) & $106(30.54)$ & $95(26.24)$ \\
\hline Average (11- 14) & $91(26.22)$ & $101(27.90)$ \\
\hline Poor (6 -10) & $150(43.22)$ & $166(45.86)$ \\
\hline Total & $\mathbf{3 4 7}$ & $\mathbf{3 6 2}$ \\
\hline
\end{tabular}

TABLE 4 ASSOCIATION OF SOCIAL SCORE \& ITS IMPACT ON MORBIDITIES (URBAN -RURAL)

\begin{tabular}{|c|c|c|c|c|c|c|}
\hline & Good & Average & Poor & Total & Chi-square & P value \\
\hline \multicolumn{7}{|c|}{ Urban Morbidity } \\
\hline Yes & 50 & 25 & 52 & 127 & \multirow[t]{3}{*}{8.6124} & \multirow[t]{3}{*}{$P<0.05$} \\
\hline No & 56 & 66 & 98 & 220 & & \\
\hline Total & 106 & 91 & 150 & 347 & & \\
\hline \multicolumn{7}{|c|}{ Rural Morbidity } \\
\hline Yes & 67 & 44 & 113 & 224 & \multirow[t]{3}{*}{20.9874} & \multirow[t]{3}{*}{$P<0.05$} \\
\hline No & 28 & 57 & 53 & 138 & & \\
\hline Total & 95 & 101 & 166 & 362 & & \\
\hline
\end{tabular}

\section{Figures}

FIGURE 1 CURRENT FINANCIAL POSITION OF THE STUDY SUBJECTS

$$
\text { Urban Rural }
$$

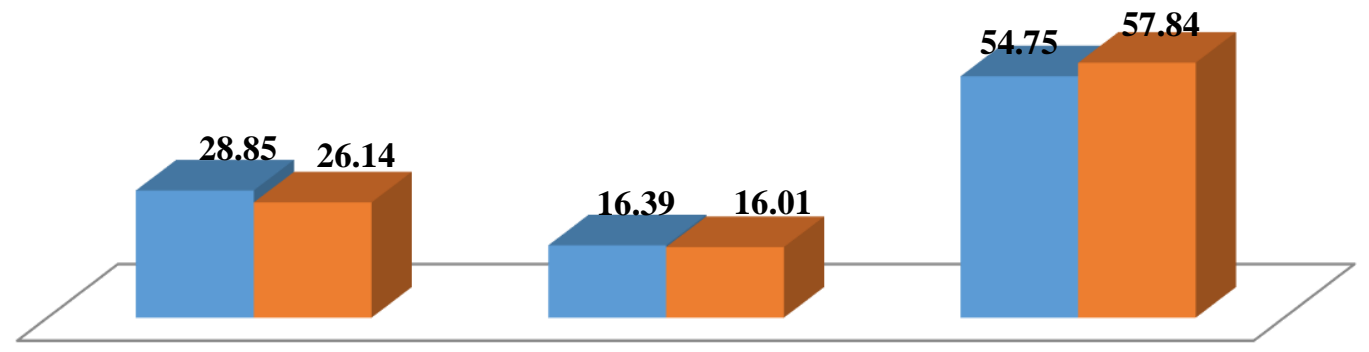

Independent

Partly dependent

Totally dependent 